\title{
LECLERC, A.
}

\section{Uma Introdução à Filosofia da Mente. Curitiba: Appris, 2018. 153 p.}

\author{
Bruno Tenório Coelho \\ Universidade Federal da Bahia (UFBA) \\ Orcid 0000-0001-7668-2755 \\ brcoelh00@gmail.com
}

Resumo: Uma Introdução à Filosofia da Mente do filósofo André Leclerc, apresenta os principais problemas, teorias e argumentos da filosofia da mente. Uma primeira questão que guia o livro é: Qual a natureza dos estados mentais? O livro apresenta diversas definições do que seriam os estados mentais, destacando-se o conceito de intencionalidade. Uma outra questão que recebe atenção é o problema mente-corpo. Descreve-se as principais teorias que buscam respondê-lo, assim como distinções e noções filosóficas centrais, avançadas pelos filósofos que abordaram o problema. O livro considera também, em com uma conclusão extensa, o lugar da mente em uma compreensão mais abrangente do universo.

Palavras-chave: filosofia da mente; estados mentais; fisicismo.

Abstract: Uma Introdução à Filosofia da Mente presents the main problems, theories and arguments of philosophy of mind. A first question guiding the book is: What is the nature of mental states? The book presents several definitions of what mental states would be, highlighting the concept of intentionality. Another issue that gets attention is the mind-body problem. It describes the main theories that seek to answer it, as well as the central philosophical distinctions and no- 
tions advanced by the philosophers who approached the problem. The book also considers, in an extended conclusion, the place of the mind in a more comprehensive understanding of the universe.

Keywords: philosophy of mind; mental states; physicalism.

A filosofia da mente é uma das áreas centrais da filosofia, que possui uma relação direta com as pesquisas em ciência cognitivas. Apesar da centralidade, a presença de obras introdutórias que detalhem os problemas filosóficos da área e as principais teorias que buscam responder a estes problemas, ao menos em língua portuguesa, são poucas. Em geral, a maior parte da literatura existente está em língua inglesa, o que dificulta o acesso às discussões ao leitor interessado. Com a chegada de Uma Introdução à Filosofia da Mente (2018) escrita por André Leclerc da Universidade de Brasília, a situação muda. Temos agora uma obra atualizada que serve como guia introdutório a filosofia da mente. No livro, avalia-se as seguintes questões: Qual o domínio do mental? O que é a consciência? Qual a natureza da intencionalidade? Como corpo e a mente se relacionam? É possível reduzir os estados mentais aos estados cerebrais? Além de expor as principais teorias que buscam responder a estas questões, há um detalhamento das principais noções filosóficas que guiam o debate especializado.

Estruturalmente o livro divide-se em duas partes. A primeira destina-se a questão "Qual o domínio do mental?". Busca-se inicialmente delimitar o que caracteriza os estados mentais, avaliando se há um critério que defina estes estados. Na parte II, discute-se as diversas correntes que respondem à questão "Como o corpo se relaciona com a mente?". Por fim, na extensa conclusão, avalia-se a partir de uma perspectiva mais alargada, o lugar da mente no universo. Iremos neste texto seguir a estrutura do livro, expondo as ideias das partes I e II, finalizando com uma avaliação geral.

Se formos traçar as origens da filosofia da mente, iremos notar que questões filosóficas sobre a mente estão presentes desde Platão e Aristóteles, os quais possuíam concepções 
próprias do que constitui um ser pensante. No entanto, quase que paradoxalmente, a filosofia da mente é também uma disciplina recente. Em termos contemporâneos, a retomada ocorre em duas obras: The Concept of Mind de G. Ryle (1949) e as Investigações Filosóficas de L. Wittgenstein (1953). No primeiro caso há uma preocupação dupla: (i) inicialmente, apresentar uma visão conciliatória sobre a mente que tanto cientistas como filósofos aceitem; e (ii) criticar a "doutrina oficial" que até então reinava, uma concepção com influência religiosa e forte teor metafísico. A crítica de Ryle, vista por muitos como necessária, permitiu novos modos de se pensar a mente. No caso das Investigações, atenta-se para o vocabulário mentalista, no uso de termos como "crença", "desejo" e "percepção". Wittgenstein pensava que diversos problemas filosóficos surgiam devido às confusões conceituais que resultavam do uso destes termos. A partir das duas obras novas questões surgiram: Qual a relação entre mente e corpo vivo? Como nossas representações (crenças, desejos e intenções) adquirem esse poder de representar? O que é uma disposição? É possível uma ação livre? Há representações mentais?

Após traçar estas considerações iniciais, Leclerc apresenta uma definição que considera razoavelmente pacífica de mente: "um conjunto de poderes de representar/sentir algo para um sujeito consciente e situado" (p. 14). A partir desta definição, pode-se exemplificar o que comumente entendemos por mental: percepções externas, sensações, imagens mentais, atitudes proposicionais, emoções e disposições. Para o não iniciado, algumas noções podem não ser familiares. Sendo assim, o autor passa a definir os termos. Perceber é ser capaz de aplicar conceitos ao identificar e classificar o que se percebe. As sensações, são os aspectos qualitativos da experiência consciente, como ver um objeto vermelho ou provar uma refeição amarga. As atitudes proposicionais, por sua vez, são estados mentais com conteúdo conceitual. Por exemplo, acreditar que a Seleção Brasileira vai ganhar a próxima Copa do Mundo. Delimita-se assim, de maneira provisória, que estados, eventos, atos ou atividades são o que consideramos pertencendo ao domínio do mental. Leclerc, ao apresentar esta delimitação do mental, faz 
uma colocação importante: "não existe nada que seja mais íntimo para nós que nossa própria vida mental” (p. 36). As pessoas têm um contato direto com suas próprias mentes. Este aspecto subjetivo, ou como se diz por vezes, a perspectiva de primeira pessoa, é algo central a compreensão que temos do mundo. A perspectiva de primeira pessoa, além disso, contrasta de maneira significativa com a pesquisa científica, que é desenvolvida largamente em terceira pessoa, por isso: "Um dos maiores desafios da filosofia da mente, talvez, seja justamente pensar essas duas concepções de forma equilibrada, ou determinar se elas são compatíveis e até que ponto, ou ainda se devemos adotar uma postura mais radical e rejeitar, por exemplo, a concepção popular" (p. 37).

A solução para esta tensão divide os filósofos ainda hoje. Até que ponto o acesso a nossa mente nos permite fazer afirmações sobre sua estrutura e funcionamento? Sabe-se atualmente que a introspecção não é um método de investigação confiável. O que reportamos sobre nossa experiência nem sempre corresponde ao que ocorre de fato. Devido a isto, o melhor a se fazer é buscar critérios objetivos ao estudar a mente. As pesquisas em ciência cognitiva das últimas décadas, buscou justamente estes critérios objetivos, através das diversas disciplinas que investigam a natureza da cognição: psicologia, neurociência, ciência da computação, linguística e antropologia. Devido a esta gama de disciplinas, estuda-se a mente a partir de diversos métodos. Ainda assim, pode-se perguntar: há algo distintivo na abordagem filosófica? Leclerc nos diz que os filósofos adotam a "análise conceitual". A análise conceitual consiste em "refletir sobre os princípios e categorias que subjazem à compreensão que temos de nós mesmos enquanto seres providos de uma mentalidade, tentando apresentar uma forma unificadas de representação que resolve ou dissolve problemas, perplexidades ou paradoxos" (p. 12).

Após esta clarificação conceitual, Leclerc apresenta o problema da causação mental, que consiste em saber como nossos pensamentos podem afetar o mundo. Ora, pode-se perguntar, como minha intenção de levantar o braço gera o movimento de levantá-lo? Ou numa questão mais intrigante, 
como o ato de representar aspectos do mundo deve ser entendido? Quais animais ou organismos possuem vida mental? Ou já agora, pode um computador ser consciente, ou mesmo um termostato? Essas questões estão na interseção da filosofia com as ciências cognitivas. Algumas destas permanecem em aberto, outras, como o estudo da cognição animal, vem obtendo avanços notáveis, ao identificar a sofisticação e complexidade das outras espécies ao solucionar os diversos problemas adaptativos que enfrentam.

Devido a pesquisa interdisciplinar em filosofia da mente, diversos filósofos propuseram a "naturalização" da filosofia. W. Quine é o maior responsável por esta proposta. De acordo com ele, a filosofia tem de estar em continuidade com a pesquisa científica ${ }^{1}$. Leclerc está de acordo, pois: "uma concepção da filosofia como campo de investigação completamente separada da investigação científica é historicamente insustentável e totalmente contraproducente" (p. 39). Apesar dos avanços científicos notáveis, nas ciências cognitivas e em outras disciplinas, há filósofos como D. Chalmers e T. Nagel que sustentam uma irredutibilidade dos estados mentais ou cerebrais. Segundo eles, não temos até o momento uma resposta satisfatória que dê conta dos aspectos qualitativos da experiência consciente. Em uma proposta mais radical, chamada de fechamento cognitivo (McGinn 1993), o problema da consciência jamais será solucionado, pois se trata de um problema insolúvel para nós. Segundo McGinn, há problemas que são insolúveis para os seres humanos, devido à natureza de nossa estrutura cognitiva.

Há diversos estados mentais, mas há algum aspecto essencial a mente? Algo que a caracteriza e diferencia, uma marca do mental? Duas características se apresentam como candidatas: a intencionalidade ou capacidade de representar e a consciência. Define-se intencionalidade como a "característica de atos, eventos e estados mentais de terem um objeto, conterem um objeto representado (existente ou não), ou de serem acerca de algo, ou ainda de serem orientados para um objeto (ou es-

$1 \quad$ Note-se que apesar da sugestão, Quine continuou a filosofar da mesma maneira de antes, e não a realizar experimentos em psicologia, recomendação feita a outros filósofos. 
tado de coisas ou fato" (p. 42). Na história da filosofia, Franz Brentano (1838-1917) introduziu o conceito. Brentano argumentou que nenhum fenômeno físico exibe esta capacidade, e que devido a isto, a intencionalidade delimita o domínio do mental. Em outras palavras, todo fenômeno mental é intencional, e o mental tem essa característica em exclusividade. Apesar de o livro se apresentar como pertencente à tradição analítica, há a discussão de noções desenvolvidas pela tradição fenomenológica, uma corrente filosófica proeminente na filosofia do século XX. Como aponta Leclerc, os fenomenólogos deram uma atenção especial ao conceito de intencionalidade. Por exemplo, Husserl assim como Searle, distingue os componentes da estrutura intencional em: modo psicológico, o conteúdo representacional e o objeto intencional. O modo psicológico determina o tipo de estado mental, se é uma crença, um desejo ou uma lembrança. O conteúdo representacional é o ato que distingue um estado intencional de outros do mesmo tipo, e finalmente, o objeto intencional é o objeto representado, o qual é determinado pelo conteúdo representacional. Acerca dos objetos intencionais, algumas questões filosóficas podem ser avançadas. Por exemplo, podemos imaginar objetos intencionais inexistentes como sereias, Pégaso e Eldorado, mas nenhum destes possui uma existência concreta. Como lidar com esta capacidade? Não parece haver nada em comum entre os objetos ficcionais a não ser o fato de serem objetos de pensamento. Dar sentido a natureza dos objetos ficcionais é uma questão filosófica em aberto, e tem relevância para a compreensão da literatura e de outros tipos de narrativa. Outra questão que pode ser feita sobre o conceito de intencionalidade é a seguinte: todo ato ou evento mental é intencional? Há quem argumente que não, como Searle. Ele dá o exemplo da dor. Quando sentimos uma dor ela é acerca de que? Não parece haver um objeto intencional do qual a dor é. Por outro lado, há filósofos como Michael Tye e Tim Crane que mantém a tese de Brentano. Eles argumentam que as dores são representações sensoriais, pois elas representam estados físicos do corpo. Assim, quando sofro um golpe, a dor que sinto é representada indicando um determinado lugar do corpo. O mesmo ocorre com outras sensações. Cabe perguntar, acerca desta proposta, se o conteúdo dos estados mentais irá 
envolver, por exemplo, conceitos. De acordo com autores que defendem a centralidade da intencionalidade, os conteúdos não são conceituais. Nesta acepção, muito do que se entendem por cognição não envolve conceitos. Uma outra indicação da intencionalidade em experiências sensoriais é a experiência com membros fantasmas: pacientes com membros amputados reportam sentir dor ou coceiras. Por fim, como última razão para esta tese, pode-se argumentar que há uma covariação causal do aparelho visual de acordo com as mudanças do ambiente (variações de distância e iluminação), permitindo assim que a mente rastreie os objetos.

Um outro aspecto da experiência sensorial que todos reconhecem é sua continuidade e organização temporal. Percebemos mundo em um contínuo, o qual W. James chamou de "fluxo de consciência" (stream of consciousness) e E. Husserl denominou através da expressão equivalente do alemão (Bewusstseinsstrom). Além do aspecto temporal da experiência perceptiva, há outra noção importante ao pensar os estados mentais (e as ações): as disposições. Leclerc define disposições em termos de capacidades (reconhecer rostos) e habilidades (falar uma língua e dirigir um carro). Pode-se dizer também que uma disposição permanece durante um intervalo de tempo, e que são capacidades e habilidades não-conscientes que podem determinar o que é consciente. Além disso, as disposições pressupõem uma base física e causal.

Acerca da intencionalidade, há uma distinção feita na literatura entre intencionalidade originária e derivada. De acordo com algumas propostas, a intencionalidade originária é capaz de conferir intencionalidade a outras representações, como frases, desenhos, gráficos e mapas. Nestes casos, no entanto, não há a capacidade de representar. Enquanto as representações dependem de uma mente, as representações públicas não irão depender, pois possuem intencionalidade derivada. Assim, coisas não mentais exemplificam a propriedade de serem acerca de algo. A foto de uma casa não é a casa de fato, mas é representada para quem olha e tem os recursos conceituais suficientes para identificá-la. 
Os fisicistas que buscam explicar os estados mentais através da atividade neuronal argumentam que em uma estratégia "de baixo para cima" é possível explicar a intencionalidade. Críticos dessa proposta, como H. Putnam, argumentaram que os fisicistas incorrem em um erro chamado de concepção mágica da linguagem. Assumem que a linguagem tem capacidade de produzir cadeias causais extraordinárias. Em realidade, o que confere significado a um termo são as relações causais como o ambiente. Em suma, para externistas como Putnam e não há intencionalidade intrínseca, enquanto alguns internistas irão reconhecer seu papel como fundamental. Observando o debate, pode-se afirmar que não há um acordo acerca da intencionalidade na filosofia contemporânea.

Após esclarecer os diversos modos em que os estados mentais podem ser entendidos, na segunda parte Leclerc apresenta as diversas teorias que buscam responder ao problema mente-corpo. Este problema consiste em explicar como os estados mentais podem ser explicados em termos causais, isto é, se uma explicação científica similar à oferecida a outros aspectos da realidade como átomos e células pode ser feita no caso dos estados mentais. Em uma consideração inicial, deve-se reconhecer os poderes fantásticos da mente. Podemos pensar em galáxias tão distantes com as quais nunca teremos contato, considerar o mundo subatômico, sentir uma forte emoção diante de uma sublime paisagem, manipular conjuntos transfinitos de diversos tamanhos e assim por diante. Admitir que todas estas capacidades resultam de atividade eletroquímica nos leva ao problema da lacuna explicativa. Mesmo reconhecendo nossa colocação entre outras espécies, que resultam de modificações que ocorreram ao longo de milhões de anos, fica-se com a impressão de que há algo mais a ser explicado no caso de alguns estados mentais. A mente fenomenal, das sensações e experiências sensoriais qualitativas, parece fugir a uma descrição estritamente objetiva. Uma descrição completa da neurofisiologia humana forneceria uma acerca explicação satisfatória de nossa vida subjetiva? Depende, certamente, do que entendemos por "satisfatória" e do que constitui uma boa explicação. 
Antes de expor as diversas teorias que buscam explicar o problema mente-corpo, Leclerc destaca a doutrina oficial, anteriormente criticada por Ryle, que tem origem em R. Descartes (1596-1650). Pode-se afirmar que Descartes desenvolveu em suas Meditações Metafísicas argumentos sustentando a tese de que a subjetividade é a fonte de conhecimento mais seguro que temos. Diferente do mundo material, que é contingente e sujeito às diversas mudanças, a nossa mente nos é acessível diretamente. Descartes é conhecido por ter aplicado a "dúvida metódica" ao questionar todas suas crenças, desde as mais básicas às mais sofisticadas, avaliando detalhadamente quais crenças resistiam à dúvida. Ao fim do processo de dúvida, Descartes concluiu que a única certeza obtida é de ser um ente pensante. Admitindo que sou um ser pensante, o que isso implica? De acordo com Descartes, reconhecer a existência enquanto ser pensante é uma certeza que resiste a dúvida, e pode servir como base para outras inferências. Em termos atuais, atribui-se a Descartes uma espécie de inatismo. O inatismo é a tese de que os conceitos mais básicos e simples não provêm da experiência, mas estão conosco desde o nascimento.

Uma outra tese defendida por Descartes é o dualismo de substância. Segundo ele, o mundo é feito de coisas pensantes e coisas extensas. Há, no fim, uma oposição entre corporeidade e pensamento. A conclusão de Descartes leva a uma série de problemas. O primeiro é saber como se dá esta relação entre substâncias distintas. Em última instância, como explicar a percepção e a ação a partir do dualismo? Sua resposta é de que apesar de serem substâncias distintas, há uma interação entre mente e corpo. Nesta acepção, há uma conexão causal entre intenções, vontades e desejos e a fisiologia, as quais localizam-se na glândula pineal. Esta resposta, como veio se atestar depois, está longe de ser satisfatória, e atualmente há poucos dualistas de substância. Ao menos entre filósofos profissionais.

O dualismo de propriedades, uma posição mais recente em filosofia, busca evitar os erros clássico do dualismo sem assumir um fisicismo. Este dualismo irá argumentar que os estados mentais possuem propriedades distintas dos estados físicos. Além disso, o dualista de propriedades sustenta que as 
propriedades mentais (ou psicológicas) não são redutíveis às propriedades físicas (ou não se explicam a partir dessas). $\mathrm{O}$ dualismo de predicados, sendo uma posição mais fraca, irá sustentar que para descrever o mundo precisamos de dois tipos de predicados: os predicados mentalistas e os predicados fisicistas. Donald Davidson sustentou esta última posição.

Uma tentativa diferente de solucionar o problema mente-corpo é o interacionismo clássico proposto por T. H. Huxley (1825-1895). Essa proposta argumenta que a mente não possui nenhum papel causal, ou seja, os estados mentais são "causalmente inertes". No exemplo de Huxley, o apito da locomotiva utiliza o vapor gerado para produzir o som, mas o som gerado não contribui para o avanço da locomotiva. Em resumo, os estados mentais são epifenômenos. Apesar da estranheza, essa proposta teórica tem um pressuposto bastante difundido entre cientistas: o fechamento causal do mundo físico. De acordo com esta tese, somente um evento físico pode causar mudanças em um sistema físico. O interacionismo, assim como o dualismo, recebe atualmente poucos adeptos entre os filósofos.

A teoria seguinte a ser exposta por Leclerc, vem em três versões, os behaviorismos: metodológico, ontológico e lógico. J. B. Watson (1878-1958) é o fundador do behaviorismo. A principal tese de Watson é a rejeição da introspecção como fonte confiável de conhecimento sobre os estados mentais. $\mathrm{O}$ pressuposto por trás desta proposta é de que enquanto ciência, a psicologia deveria manter suas observações objetivas e controláveis. A mente é uma caixa preta que pode ser observada somente a partir de sua resposta a estímulos. Devido a isto, os behavioristas foram bastante criticados. Ora, não nos parece que a mente seja inacessível, afinal, conhecemos ao menos uma, a nossa. Este princípio metodológico, argumentam os behavioristas, é melhor visto como um pressuposto de pesquisa, pois não implica necessariamente a negação de uma vida mental. Diferente desta proposta, o behaviorismo ontológico irá sustentar que eventos, atos e estados mentais vividos em primeira pessoa não existem. O behaviorismo lógico, por sua vez, difere das duas versões anteriores, pois: "corresponde a um programa de tradução das expressões e conceitos que nós 
usamos para falar sobre a mente, em frases condicionais que não contêm mais nenhuma referência a estados ou eventos mentais" (p. 91). Entre os behavioristas há uma preocupação em descrever corretamente os estados mentais, isto é, em fornecer uma explicação objetiva do que fazemos e porquê. Ryle, assim como Russell, Carnap e Hempel, sustentavam que deveria haver um estudo científico da mente que a colocasse como parte da teia causal do mundo.

Após a perda de espaço do behaviorismo no fim dos anos 50, uma proposta diferente ganha espaço: o materialismo ou tese da identidade mente-cérebro. Em uma avaliação inicial, o materialismo não parece uma teoria muito inovadora, pois parte de observações relativamente incontroversas da conexão entre a mente e o cérebro. Por exemplo, se batermos forte com a cabeça iremos ter possivelmente efeitos em funções cognitivas como a memória, o uso de álcool leva a embriaguez e atitudes descontroladas e o uso de medicamentos agindo no sistema nervoso afetam a percepção. Filósofos como U. T. Place, H. Feigl, J. J. C. Smart e D. Armstrong, estão entre os autores que defenderam o materialismo. De acordo com esta proposta, estados mentais e estados cerebrais são uma coisa só. Quando reportamos uma dor, por exemplo, estamos apenas reportando algo que ocorreu internamente. Os materialistas inspiram-se na identidade bem-sucedidas atingidas pela pesquisa científica: a temperatura do gás é a energia cinética média das moléculas, genes são sequências de DNA e assim por diante. A identidade, nesta acepção, resulta da observação de descobertas empíricas bem-sucedidas na história da ciência. Por indução, espera-se que outras identidades sejam descobertas. Os materialistas supõem que o mesmo irá ocorrer com os estados mentais.

Um esclarecimento acerca da noção de identidade precisa ser feito. Na definição comumente aceita, a Lei de Leibniz ou Lei da Indiscernibilidade dos Idênticos atesta que: "Para qualquer x e qualquer y, se x e y são idênticos, então para qualquer propriedade P, x tem P se e somente se y tem P" (p. 103). Sendo assim, se os estados mentais são estados cerebrais, o que temos são descrições diferentes para o mesmo fenômeno, mas que não implica uma entidade separada. A teoria da identidade 
vem em duas versões: a teoria tipo-tipo e a ocorrência-ocorrência. A distinção pode ser feita do seguinte modo, se escrevemos a palavra "Moça" três vezes no papel, pode-se perguntar quantas palavras há escrita. Se pensarmos nas ocorrências particulares iremos responder "três", mas se tomarmos o modelo ou padrão abstrato iremos responder "uma". Neste último caso, interessa-nos a propriedades que os exemplares exibem, independente das instâncias individuais. Duas objeções surgem contra a teoria da identidade. A primeira objeção sustenta-se na noção de realizabilidade múltipla. Esta noção pode ser explicada do seguinte modo. Os mesmos sistemas, como a dor, estão instanciados em espécies diferentes, as quais possuem estruturas cognitivas distintas. Se os estados mentais são estados cerebrais, isto é, se a teoria da identidade estivesse correta, organismos ligeiramente diferentes de nós não poderiam sentir dores, já que em boa parte dos casos, a estrutura na qual a dor é implementada é mais simples. Uma segunda objeção sustenta que propriedades fenomenais não são abarcadas pelos padrões neurais. De acordo com esta objeção, nossa experiência subjetiva, em toda sua extensão e variedade, não é captada pela descrição científica de terceira pessoa.

O funcionalismo é outra teoria que ganhou força e figura atualmente como uma das propostas centrais em filosofia da mente. O funcionalista constrói justamente da crítica apontada no parágrafo anterior à teoria da identidade, através do argumento da realizabilidade múltipla. Leclerc ao considerá-lo, afirma: "se é razoável pensar que seres com uma constituição física ou uma biologia diferente da nossa podem sentir dor, então, o que importa, afinal, não é em que tipo de matéria os estados mentais são realizados fisicamente, mas o que eles fazem" (p. 111). O termo central desta tese é função. De acordo com filósofos como D. Dennett, J. Fodor e D. Lewis, o que importa na identidade de um estado mental é o papel que exerce. Mais especificamente: as relações causais entre as experiências sensoriais (input), os estados internos do organismo e o comportamento (output). Nesta definição, estados mentais podem ser exibidos por sistemas artificiais feitos de silício ou em qualquer outro substrato que obedeça a estes padrões causais. $\mathrm{O}$ 
funcionalismo apoia-se na analogia com os computadores: a mente está para o software assim como o cérebro está para o hardware. O conceito de Máquina de Turing é utilizado por filósofos para definir os estados mentais. Esta Máquina, em termos gerais, é um dispositivo abstrato que descreve matematicamente a computação de instruções. Ela estrutura-se do seguinte modo, tem-se uma fita dividida em quadrados ilimitada, um cabeçote que lê as instruções em ambas as direções, e um conjunto pré-estabelecido de instruções. De acordo com a analogia, o cérebro opera da mesma forma, recebendo inputs do ambiente através dos órgãos sensoriais, processando estes sinais e gerando os outputs através das ações.

Algumas críticas feitas ao funcionalismo atacam a analogia feita com a Máquina de Turing. A objeção centra-se nas diferenças entre cérebros e computadores. Enquanto na máquina de Turing os estados representados são sempre totais, no caso dos estados mentais humanos não se pode falar o mesmo. Talvez possamos apresentar a questão em termos de graus e afirmar que esta máquina precisa ser dotada de uma complexidade apropriada. Mas qual seria um grau apropriado? Sendo o computador uma máquina que obedece a regras estritas, não parece, à primeira vista, que um aumento de complexidade irá resultar em estados mentais similares aos nossos. Uma objeção diferente afirma que o funcionalismo não explica a consciência. Seriam os aspectos qualitativos da experiência explicáveis através das relações causais? Na famosa crítica de Searle ao funcionalismo, uma máquina de Turing compreenderia sintaxe, mas não a semântica dos termos.

Na tentativa de evitar os diversos problemas que surgem quando se tenta descrever os estados mentais, o casal Churchland propôs que abandonássemos por completo o discurso que se refere a eles. A compreensão que temos quando descrevemos crenças, desejos e intenções é em última instância incorreta. No jargão filosófico, as atitudes proposicionais ou o modelo crença-desejo seria falso. Uma das motivações centrais para esta proposta se dá no crescimento vertiginoso das neurociências. Segundo eles, a psicologia popular, o modelo crença-desejo que utilizamos para compreender o comportamento das 
pessoas corriqueiramente seria redutível às descrições neurais. Esta afirmação feita a algumas décadas tinha como esperança um avanço da neurociência para uma ciência que superaria as explicações psicológicas. Estamos em 2019, e algo assim não ocorreu. Neurociência e psicologia permanecem como disciplinas distintas, ainda que em colaboração intensa. O pressuposto do eliminista de que haveria um avanço na direção de uma redução se mostrou infundado ${ }^{2}$; dificilmente a descrição neural por si só dá conta da complexidade do comportamento e da vida mental dos indivíduos.

O monismo anômalo desenvolvido por D. Davidson é também uma proposta em filosofia da mente que tenta explicar a relação entre corpo e mente. Este tipo de monismo sustenta que "somos seres materiais, e os conceitos mentalistas que utilizamos não são redutíveis aos conceitos da física ou das ciências da natureza (física, química e biologia), e não existem leis causais estritas entre os eventos mentais e os eventos físicos" (p. 150). Leclerc descreve a ontologia de eventos que este monismo sustenta. Eventos são particulares limitados temporalmente e cuja complexidade é variável. Em outras palavras, um mesmo evento pode ser descrito de diversas maneiras, envolvendo o vocabulário mental em algumas vezes e em outras envolvendo termos físicos. Na definição: para qualquer evento mental, deve existir uma descrição sob a qual o mesmo evento é físico. Logo, o mental é o físico. Uma outra denominação para esta proposta é de "fisicismo de ocorrência" pois identifica a ocorrência mental "sentir dor" com a ocorrência de um evento físico particular como "inervação das fibras nervosas C". Apesar desta identidade, Davidson argumenta que há uma irredutibilidade do vocabulário mentalista. A relação entre físico e o mental se dá através de outra relação: a superveniência. A relação de superveniência é uma relação entre dois grupos de propriedade: o grupo das propriedades de base e o grupo das propriedades supervenientes, sendo que o primeiro grupo determina

2 Em língua portuguesa é comum encontrarmos os termos "eliminativismo" ou "materialismo eliminativo" para designar a proposta desenvolvida pelos Churchland. O termo "eliminista" utilizado pelo autor é raramente encontrado. Apesar disso, mantive a tradução feita por Leclerc. Agradeço a um dos revisores por notar a tradução incomum. 
o segundo. Por exemplo, a madeira é determinada por sua estrutura molecular, assim como a liquidez da água é realizada fisicamente em suas forças intermoleculares.

Leclerc apresenta em seguida o naturalismo biológico desenvolvido por J. Searle. Searle é um crítico do funcionalismo, e por conseguinte, do modelo computacional da mente. As questões centrais de Searle são as seguintes: Como a intencionalidade é possível? Como estados mentais com conteúdo proposicional podem ser acerca de algo? Para responder às duas questões ele apresenta duas noções: de Rede e a de Pano de Fundo. A rede seria o conjunto de atitudes proposicionais mantidas pelo indivíduo, as quais estão interligadas e são interdependentes. Esta rede, no entanto, pressupõe um Pano de Fundo, uma camada mais profunda que não é constituída por representações. De acordo com Searle, este Pano de Fundo é constituído pelos pressupostos que carregamos acerca das regularidades do mundo, como ter um campo gravitacional. $\mathrm{O}$ naturalismo biológico sustenta-se em dois aspectos: (i) cérebros causam mentes; e (ii) os estados mentais são características da ordem superior do cérebro. Como indica Leclerc: "eventos mentais são fenômenos biológicos, comparáveis à digestão, a respiração e a circulação sanguínea" (p. 168). A posição de Searle tenta compatibilizar diferentes propostas: assim como os eliministas, ele admite que o mundo é constituído por eventos físicos, mas ao mesmo tempo, admite a irredutibilidade dos fenômenos mentais. De acordo com ele, os fenômenos mentais existem subjetivamente. Searle admite que dois tipos de intencionalidade são essenciais: percepção e ação. Estas duas determinam poderes causais, pois os estados mentais são de ordem superior. De acordo com Searle e contrário a descrição clássica, a relação entre causa e efeito é lógica. Segundo ele, a inervação dos neurônios individuais causa e realiza a intenção-na-ação, e também causa mudanças fisiológicas. Contudo, a causação não é a mesma. Como esperado, muitos criticaram Searle por tentar obter o melhor de dois mundos sem solucionar o problema de fato. Trata-se talvez de um dualismo disfarçado.

A última proposta a ser avaliada são as duas versões de fisicismo: o reducionista e o não reducionista. Enquanto o 
primeiro busca reduzir o mental ao físico, o segundo sustenta que o mental sobrevém ao físico, mas não se reduz a este. Esta proposta, presente na obra de Jaegwon Kim, gira em torno da noção de superveniência. Kim defende a versão reducionista do fisicismo. O fisicismo é a tese de que todos os fatos são físicos ou dependem estritamente de fatos físicos. A definição, contudo, não elimina incongruências, já que a física enquanto disciplina também possui os seus desacordos. Leclerc apresenta alguns pressupostos da física. O primeiro é a generalidade da física: todos os objetos que existem no espaço-tempo têm propriedades físicas, e as leis da física governam o comportamento de todos esses objetos e eventos. O segundo é a completude da física: todo evento físico possui uma causa física que é suficiente para sua ocorrência. Em seguida há o fechamento causal da física, que indicamos antes. Por último, o princípio da exclusão causal: se um evento E tem uma causa suficiente $C$ no momento $t$, então nenhum outro evento distinto de $C$ pode ser a causa de E. Há também um princípio metafísico: ser é possuir poderes causais. Além disso, é importante notar que as propriedades de ordem superior não introduzem nenhum novo poder causal. Sendo assim, todas as propriedades das ciências especiais reduzem-se as propriedades físicas. Kim utiliza estes princípios para argumentar contra o fisicismo anti-reducionista. De acordo com ele, a noção de superveniência acaba por tornar a causação mental ininteligível. Sua solução busca integrar o mental ao físico, reduzindo as propriedades mentais às propriedades físicas, relativizando estas a uma espécie particular. A redução de Kim se revela uma redução funcional.

Na parte final do livro, após expor as virtudes e limitações das teorias mais importantes da filosofia da mente, Leclerc apresenta na conclusão uma perspectiva mais alargada do lugar na mente no universo. Se pensarmos no estágio atual em que a humanidade se encontra, iremos reconhecer que a principal diferença em relação a períodos anteriores é a visão científica de mundo. Em uma narrativa comum, o universo tem uma história que inicia com o Big Bang. Com o passar do tempo, a poeira estelar forma os planetas e galáxias. Em um planeta específico, a Terra, a vida surge. Os organismos primordiais aparecem a 
milhões de anos atrás e vem se modificando ao longo do tempo através da seleção natural, atingindo níveis de complexidade mais elevados. Por fim, surgem seres conscientes capazes de pensar a si mesmo e todo o resto.

A partir de nossas melhores teorias, sabe-se acerca da constituição material do universo, desde o muito pequeno, estudado pela mecânica quântica, até o muito grande, a qual a teoria da relatividade descreve. Esta visão científica de mundo, certamente, não é completa: há inúmeras lacunas em nosso conhecimento. Apesar disso, há quem pense que o fisicismo é a proposta mais próxima da verdade, pois se adequa com uma descrição da realidade que se respalda em séculos de investigação. Sobre o fisicismo podemos perguntar: Uma descrição puramente física consegue dar conta dos diferentes fenômenos estudados pela ciência? Pensemos em diferentes tipos de eventos: as movimentações no mercado financeiro, os fatos históricos como o nascimento de Napoleão, o comportamento das aves e assim por diante. Será que uma explicação estritamente fisicista abarca todos estes eventos? Há razões para questionar a plausibilidade do fisicismo. Se admitirmos que diferentes explicações fornecidas por diferentes ciências não podem ser facilmente descartadas, então explicações psicológicas, incluindo-se aqui àquelas fornecidas pela psicologia popular, permanecerão conosco por um bom tempo. Pode-se argumentar, adicionalmente, que algumas destas explicações são necessárias para um entendimento geral dos seres humanos enquanto agentes livres e autônomos.

Poucas obras introdutórias dão conta da riqueza dos argumentos dos filósofos sem os trivializar. A filosofia da mente, por ser uma das áreas mais ativas das últimas décadas, apresenta uma variedade de argumentos e teorias nem sempre fáceis de se compreender, devido a riqueza de detalhes e pormenores. Leclerc os apresenta de forma clara e rigorosa, sem deixar de demonstrar, quando necessário, a sofisticação necessária. $\mathrm{O}$ leitor curioso, além de todo o conteúdo exposto no livro, tem ao final uma bibliografia com as principais obras mencionadas, caso queira se aprofundar na discussão especializada. 


\section{Referências}

RYLE, G. The Concept of Mind. Londres: Barnes \& Noble, 1949.

MCGINN, C. Problems in Philosophy: The Limits of Inquiry. Oxford: Blackwell, 1993.

WITTGENSTEIN, L. Investigações Filosóficas. Petrópolis: Vozes, 2009. 